\title{
Impact of Weather Index Insurance on Groundnut Farmers' Technical Efficient in Senegal: A Propensity Score Matching Approach
}

\author{
Baoubadi Atozou ${ }^{1,2,3}$, Kotchikpa Gabriel Lawin ${ }^{1,2}$ \& Diombare Niang ${ }^{2}$ \\ ${ }^{1}$ Center for Research on the Economics of the Environment, Agri-food, Transports and Energy (CREATE), \\ Laval University, Quebec, Canada \\ ${ }^{2}$ Department of Agri-food Economics and Consumer Science, Laval University, Quebec, Canada \\ ${ }^{3}$ Egg Industry Economic Research Chair, Laval University, Quebec, Canada \\ Correspondence: Baoubadi Atozou, Department of Agri-food Economics and Consumer Science, Laval \\ University, Quebec, Quebec, G1V 0A7, Quebec, Canada, Tel: 1-581-777-4874. E-mail: \\ baoubadi.atozou.1@ulaval.ca
}

Received: July 11, 2017 Accepted: August 21, $2017 \quad$ Online Published: September 29, 2017

doi:10.5539/jsd.v10n5p131 URL: https://doi.org/10.5539/jsd.v10n5p131

\begin{abstract}
Irregular and low rainfall levels and drought have become important sources of low agricultural yields and agricultural incomes in sub-Saharan Africa. Weather index insurance is a financial product for climate risk management aimed at securing farmers' incomes. This paper aims to evaluate the impact of a weather index insurance project piloted with groundnut farmers in Senegal in 2015-2016 agricultural season on farmer's technical efficiency (TE). A Stochastic Production Frontier model was used to estimate the TE scores. A matched group of beneficiaries and control farmers was determined using propensity score matching techniques to mitigate biases stemming from observed variables. The results showed that average TE is consistently higher for control farmers than the beneficiary group. Age, gender and education were found to be significantly related to technical efficiency, while membership in farmers' association, credit, improved seeds and extension contact were not significantly related to technical efficiency. From a policy perspective, we suggest that weather index insurance programs targeting smallholder farmers in developing countries, and particularly in sub-Saharan Africa, be accompanied with education services, provision of new technologies such as high yield seeds and other best farm management practices and credit to help farmers better adapt to weather shocks and secure their production and income.
\end{abstract}

Keywords: technical efficiency, stochastic frontier, inefficiency, weather index insurance, Senegal, Propensity Score Matching

\section{Introduction}

The agricultural commodities production are subjects to many risks which cause distortions on the farmer productivity and therefore on their output. Many of these risks, include climates risks, biological risks, irregularity of rain and the invasion of insects, are out of farmer's control. In addition, market risks and perishability of the commodities, the world commodities volatility, and the difficulty to have the goods and perfect market information are others risks that farmers should manage to improve their income. Smallholder farmers in developing countries face enormous challenges to adopt strategies that mitigate the impact of climates risks on their output. Therefore, Non-Governmental Organizations (NGOs) and international institutions including World Bank and African development Banks, are implementing many projects and programs to help farmers to manage production risks in order to ensure sustainable agricultural growth and poverty alleviation.

Many instruments such as micro-credit services, diffusion of new technologies including improved seeds and recently weather index insurance are used by NGOs and international institutions to achieve this main objective. While the impact of index insurance on production risk and farm income is well documented in the literature (Sivakuma and Motha 2008; Chetaille and Lagrandé, 2010; Hazell and al. 2010; Burke, Janvry and Quintero 2010; Burke and al. 2010; Erec and Musshoff, 2011; Mabul et al. 2012; Clarke et al. 2012; Carter et al., 2014), there is no previous study that investigated its impact on smallholder farmers' technical efficiency in developing countries. Meanwhile, improving farm technical efficiency is an important element of agriculture based growth 
policies in order to ensure long-term sustainability of agricultural resources, food security and poverty alleviation. The main objective of this paper is to evaluate the impact of the weather index insurance program on smallholder farmers' technical efficiency in Senegal using stochastic production frontier function and propensity scores matching (PSM) methods.

In any impact evaluation, a primary concern in estimating program impacts is to ensure that the impact estimated is truly due to the project and not potentially biased by unobserved factors in the data. To estimate the impact of insurance program while recognizing the problem of selection bias, one needs the difference of the TE score at time $t$ between a state where the farmer is insured (treatment) and a state where the same farmer is not insured (control), denoted by the superscripts 1 and 0 . However, this is impossible to estimate because a farmer exists in one of two mutually exclusive states: either he has access to the insurance program or he does not. The challenge of impact evaluation, therefore, is to identify suitable comparison groups to compare with beneficiaries of the insurance program and hence construct the counterfactual. Randomized experiments enable the cleanest construction of the counterfactual (Duflo et al. 2008). However, the implementation of the insurance program beneficiaries did not follow a randomized experiment design to ensure the absence of selection bias. A common evaluation technique to control selection bias in quasi-experimental study like the insurance program is the propensity score matching. This approach allows selecting a comparison group like the treatment group in every way, except that it was not subject to the intervention (Bravo-Ureta, 2012).

In this paper, we use a stochastic production frontier (SPF) model to estimate TE score of groundnut farmers. We then use the PSM technique to evaluate the impact of the weather index insurance on TE following the approaches used by Godtland et al. (2004), Bernard et al. (2008) and Francesconi and Heerink (2010). We rely on primary data that we collected on beneficiaries and non-beneficiaries of the insurance program in the Kafrine region in Senegal.

The remainder of the paper is organized as follow. The materials and methods are presented in the second section. In the third section, we present the results and discussion. The fourth section concludes.

\section{Materials and Methods}

\subsection{Stochastic Production Frontier Model}

Technical efficiency results when maximum output is obtained from a given combination of resources (Iheke, 2008) such as land, labor, pesticides, herbicides, fertilizers, seeds, tractors and others inputs. A farm that operates at the production frontier has a technical efficiency of $100 \%$.

Following Meeusen and Broeck (1977), Battese and Coelli (1995), Iheke (2008), Khan et al. (2010), Khai and Yade (2011), the stochastic production frontier is specified as:

$$
\ln \left(y_{i}\right)=\beta_{0}+\sum_{j=1}^{K} \beta_{i} \ln \left(x_{i j}\right)+v_{i}-u_{i}
$$

And

$$
u_{i}=\delta_{0}+\sum_{m=1}^{l} \delta_{m} Z_{m i}
$$

Where $y_{i}$ represents the quantity of groundnut harvested in kilogram by the $\mathrm{i}^{\text {th }}$ farmer; $x_{j}$ is the vector of production inputs (land area, labour and seeds used in groundnut production); $\beta_{i}$ is a vector of parameters to be estimated; $v_{i}$ is two sided stochastic term that accounts for statistical noise and is assumed to be independently and identically distributed $N\left(0, \sigma_{v}^{2}\right)$; uncorrelated with $u_{i}$ which is nonnegative random error accounting for technical inefficiency and is assumed to be independently distributed, truncated at zero with mean $\mu_{i}=\delta_{0}+$ $\sum_{m} \delta_{m} Z_{m i}$ and variance $\sigma_{u}^{2}\left(\left|N\left(\mu, \sigma_{u}^{2}\right)\right|\right)$. The $\mathrm{Z}$ variables represent factors that may influence farmer's inefficiency and $\delta$ are the parameters to be estimated.

The $\mathrm{Z}$ variables include the age of the farmer (in years); a dummy variable representing the gender of the farmer ( $1=$ male, $0=$ female); a dummy variable representing farmer's literacy status ( $1=$ literate, $0=$ otherwise); a dummy variable used to measure if the farmer belongs to a farmer organization or association ( 1 if yes, 0 otherwise); a dummy variable to measure the use of improved seeds ( 1 if yes, 0 otherwise); a dummy variable to measure access to credit (measurement of the influence of credit constraints on efficiency) which take the value 1 if the farmer received credit in the past year, 0 otherwise; a variable representing an extension contact (dummy variable to measure the influence of agricultural extension on efficiency) which take the value 1 if the farmer has had contact with an agricultural extension officer in the past year, 0 otherwise; the distance of the plot from the homestead (in kilometers); a dummy variable used to measure if the farmer has access to the rainfall insurance which take the value 1 if yes and 0 otherwise and logarithm of the non-farm income of the farmer in the last 12 months. 
The parameters of the stochastic frontier and the inefficiency model were estimated simultaneously following the literature on stochastic frontier models. We estimate the stochastic frontier function with a maximum likelihood approach using the package developed by Kumbhakar et al. (2015) in STATA. We derive the technical efficiency that has been used as output in the PSM component of our analysis. Following Coelli and Perelman (1996) the farm-specific estimates of technical efficiency is defined by:

$$
T E_{i}=E\left[\exp \left(-u_{i}\right) \mid \varepsilon_{i}\right]=E\left[\exp \left(-\delta_{0}-\sum_{m=1}^{l} \delta_{m} Z_{m i}\right) \mid \varepsilon_{i}\right]
$$

Where $\varepsilon_{i}=v_{i}-u_{i}$ and $\mathrm{E}$ is the expectation operator.

\subsection{Propensity Score Matching Techniques}

The main objective of this paper is to measure the average impact of weather index insurance on groundnut farmers' technical efficiency. Thus, the propensity score-matching techniques were used to capture the impact of the weather index insurance on TE measured by the Average Treatment effect on the Treated (ATT). As showed by Rosenbaum and Rubin (1983), Heckman et al. (1997), Becker and Ichino (2002), Dehejia and Wahba (2002), Smith and Todd (2005), Todd (2006) and Takahashi and Barrett (2014), ATT computes the average difference in TE of groundnut farmers that were insured through the program (treatment group) and farmers without insurance (control group). The ATT is typically formalized as follows:

$$
A T T=E\left(y_{1 i}-y_{0 i} \mid T_{i}=1\right)=E\left(y_{1 i} \mid T_{i}=1\right)-E\left(y_{0 i} \mid T_{i}=1\right)
$$

Where $\mathrm{E}($.$) is the mathematical expectation operator, \mathrm{y}_{0 \mathrm{i}}$ is the TE score of insured groundnut farmer $i$ and $y_{0 i}$ the TE score of the same groundnut farmer had he/she was not insured and $\mathrm{T}$ is the treatment indicator that takes the value 1 if the farmer is insured (participate to the weather index insurance program) and 0 otherwise. The fundamental problem in estimating the ATT is that, it is impossible to observe the TE score of farmers who bought the weather index insurance had they not bought the insurance $\left(\mathrm{y}_{0 \mathrm{i}} \mid \mathrm{T}_{\mathrm{i}}=1\right) . E\left(y_{1 i} \mid T_{i}=1\right)$ is observed for farmers in treatment group and $E\left(y_{0 i} \mid T_{i}=0\right)$ for those in the control group. Rosenbaum and Rubin (1983, 1985 ) and Liverpool-Tasie et al., 2015 showed that a simple comparison of these two TE score will lead to a bias estimate of the true ATT expressed by the equation (4) below:

$$
\begin{array}{r}
{\left[E\left(y_{1 i} \mid T_{i}=1\right)-E\left(y_{0 i} \mid T_{i}=0\right)\right]=} \\
E\left(y_{1 i} \mid T_{i}=1\right)-E\left(y_{0 i} \mid T_{i}=1\right)+E\left(y_{0 i} \mid T_{i}=1\right)-E\left(y_{0 i} \mid T_{i}=0\right)\left[E\left(y_{1 i} \mid T_{i}=1\right)-E\left(y_{0 i} \mid T_{i}=0\right)\right]=A T T+ \\
E\left(y_{0 i} \mid T_{i}=1\right)-E\left(y_{0 i} \mid T_{i}=0\right)
\end{array}
$$

Where last term of the right-hand side indicates the magnitude of bias from the true ATT because the TE score between the same groups of farmers would still be different even in the absence of buying the insurance.

We use the PSM approach developed by Rosenbaum and Rubin (1983) to correct for the bias in estimating the ATT. The PSM relies on the conditional independent assumption (CIA) which states that states that treatment status is random conditional on some set of observed $\mathrm{X}$ variables. In this sense, selection on observables is analogous to an experiment, in which treatment status is unconditionally random

Under the CIA, conditional on the probability of participating in the index insurance program, given the observable characteristics, TE score in the absence insurance and participation in the index insurance program are statistically independent (Liverpool-Tasie et al. 2015):

$$
E\left(y_{0 i} \mid T_{i}=1, p\left(x_{i}\right)\right)=E\left(y_{0 i} \mid T_{i}=0, p\left(x_{i}\right)\right)
$$

Where $p\left(x_{i}\right)$ represents the probability of participating in the index insurance program given the characteristics $\mathrm{x}$, defined as: $\left(T_{i}=1 \mid x_{i}\right)=p\left(x_{i}\right)$. The CIA is non-testable. However, Rosenbaum and Rubin (1983) argued that, the CIA will be satisfied if $\mathrm{X}$ includes all of the variables that affect both (not either, but both) participation and outcomes. The second hypothesis of the PSM is the common support (Rosenbaum and Rubin 1983, 1985; D'Agostino 1998; Dehejia and Wahba 2002) i.e. the choice of control farmers (uninsured farmers) similar to treated farmers (insured farmers) according to their propensity score $p\left(x_{i}\right)$. The common support hypothesis requires substantial overlap of observable characteristics between insured and uninsured farmers (Liverpool-Tasie et al., 2015).

Under the CIA and common support hypothesis, Rosenbaum and Rubin $(1983,1985)$ showed that the bias is statistically equal to zero and that the difference between the TE score of the matched insured farmers and the 
uninsured farmers is the true estimate of the ATT. In practice, the procedure for implementing the PSM to estimate the impact of a program can be divided into three steps: (1) estimate the propensity score; (2) choose a matching algorithm that will use the estimated propensity scores to match untreated units to treated units and (3) estimate the impact of the intervention with the matched sample and calculate standard errors. In our empirical strategy, we use the Nearest Neighbor and Kernel matching algorithm.

\section{Data and Descriptive Analysis}

Weather index insurance programs are currently implementing in several sub-Saharan countries such as Mali and Burkina Faso in cotton and corn sectors, Senegal in groundnut and corn sectors, and Benin in corn sector (Muller and al. 2012). In Senegal, the Global Insurance Index Program partners with the National Company of Agriculture Insurance (CNAAS) in developing the weather index insurance for groundnut smallholder farmers. In autumn 2016, we collected data on a randomly selected sample of 305 groundnut farmers including 104 farmers who bought the index insurance (treated group) and 201 non-insured groundnut farmers (control group) in Kafrine region. Table 1 below shows key socioeconomics characteristics, agriculture input used by the sampled groundnut farmers

Table 1. Socio-economic characteristics of the unmatched sample

\begin{tabular}{|c|c|c|c|c|}
\hline Characteristics of smallholder farmers & Treated & Control & T-test & pooled sample \\
\hline \multirow{2}{*}{ Household head Age } & 42.28 & 43.76 & \multirow{2}{*}{0.89} & 43.259 \\
\hline & $(10.63)$ & $(14.85)$ & & $(13.56)$ \\
\hline \multirow{2}{*}{ Gender of household head (\%) } & 77.88 & 86.57 & \multirow{2}{*}{$1.94 * *$} & 83.61 \\
\hline & $(0.41)$ & $(0.34)$ & & $(0.37)$ \\
\hline \multirow{2}{*}{ Household head is literate $(\%)$} & 27.88 & 36.82 & \multirow{2}{*}{1.564} & 33.77 \\
\hline & $(0.45)$ & $(0.36)$ & & $(0.47)$ \\
\hline Membership in a farmers' organization & 74.04 & 24.38 & & 41.310 \\
\hline$(\%)$ & $(0.44)$ & $(0.43)$ & ת.ד & $(0.49)$ \\
\hline \multirow{2}{*}{ Use improved Seeds (\%) } & 50.96 & 34.33 & \multirow{2}{*}{$-2.838 * *$} & 40 \\
\hline & $(0.50)$ & $(0.47)$ & & $(0.49)$ \\
\hline \multirow{2}{*}{ Quantity of seeds used (Kg) } & 425.91 & 309.69 & \multirow{2}{*}{$-3.002 * * *$} & 349.32 \\
\hline & $(413.91)$ & $(259.55)$ & & $(324.67)$ \\
\hline \multirow{2}{*}{ Access to credit $(\%)$} & 42.31 & 28.36 & \multirow{2}{*}{$-2.47 * *$} & 33.11 \\
\hline & $(0.49)$ & $(0.45)$ & & $(0.33)$ \\
\hline \multirow{2}{*}{ Distance from home to farm $(\mathrm{Km})$} & 1.64 & 1.98 & \multirow{2}{*}{$2.060 * *$} & 1.87 \\
\hline & $(1.18)$ & $(1.42)$ & & $(1.35)$ \\
\hline \multirow{2}{*}{ Labor used (number of days) } & 375.86 & 463.69 & \multirow{2}{*}{$2.30 * *$} & 433.73 \\
\hline & $(292.31)$ & $(326.12)$ & & $(317.27)$ \\
\hline \multirow{2}{*}{ Land area (ha) cultivated } & 4.259 & 3.31 & \multirow{2}{*}{$-2.74 * * *$} & 3.63 \\
\hline & $(3.70)$ & $(2.29)$ & & $(2.88)$ \\
\hline \multirow{2}{*}{ Access to extension services $(\%)$} & 22.12 & 16.42 & \multirow{2}{*}{-1.21} & 18.36 \\
\hline & $(0.41)$ & $(0.37)$ & & $(0.38)$ \\
\hline \multirow{2}{*}{ Non-farm income (XOF) } & 221563.90 & 207393 & \multirow{2}{*}{-0.91} & 212225.04 \\
\hline & $(335339.4)$ & $(400492.1)$ & & (379489.6) \\
\hline Production $(\mathrm{Kg})$ & $1739.81(3030.08)$ & $\begin{array}{c}1731.23 \\
(2434.64)\end{array}$ & -0.03 & $1735.15(2647.73)$ \\
\hline Obs. & 104 & 201 & & 305 \\
\hline
\end{tabular}

$* * *$ Significant at $1 \%$, ** significant at 5\% level and * significant at $10 \%$ level, (.) Standard Deviation 
Table 1 shows that farmers in our sample are relatively old with an average age of 43 years. Around $84 \%$ of the households surveyed are headed by males. One in three of the household heads are literate and $41 \%$ are members of farmer organization. Groundnut households have challenges accessing agricultural assets, new technology and credit. Indeed, only $40 \%$ of them reported using improved seeds and 33\% have access to credit through a formal credit institution for their agricultural activities. Access to extension services is also a great challenge. Only few farmers reported having access to extension services (18\%). The land area cultivated is on average less than four hectares per households.

\section{Empirically Results and Discussion}

\subsection{Technical Efficiency Measure and Determinants of Technical Inefficiency}

Table 2 presents empirical results of the stochastic production frontier model and the determinants of technical inefficiency. Consistence with other studies on technical efficiency in agricultural sector in developing countries, the results show that land is the most important input for groundnut production in Senegal. Increasing land area cultivated by one percent enhances the groundnut production by 0.512 percent. This is similar to findings from other studies in developing countries reported in Khan and al. (2010). The production elasticity of seeds and labor are 0.232 and 0.132 respectively and are statistically significant at $5 \%$ level. The elasticity of scale is 0.89 (less than 1) suggesting decreasing return to scale in the groundnut sub-sector in Senegal. This finding agrees with those of other studies in developing countries (eg: Khan and al., 2010; Kinkingninhoun-Mêdagbe et al., 2010; Khai and Yabe 2011).

Table 2. Maximum Likelihood (ML) estimates of the parameters for Stochastic Production Frontier (SPF) function and technical inefficiency determinants

\begin{tabular}{|c|c|c|c|}
\hline Ln (production in kg) & Coef. & SE & P-value \\
\hline Ln (seed used in kg) & $0.232 * * *$ & 0.079 & 0.003 \\
\hline Ln (labor used in person-days) & $0.153^{* *}$ & 0.064 & 0.016 \\
\hline Ln (land area in ha) & $0.512 * * *$ & 0.095 & 0.000 \\
\hline Constant & $4.367 * * *$ & 0.555 & 0.000 \\
\hline Scale elasticity & 0.897 & & \\
\hline \multicolumn{4}{|l|}{ Technical inefficiency component } \\
\hline Household head Age & $-0.133 * *$ & 0.067 & 0.045 \\
\hline Household head gender $(1=\text { male })^{+}$ & $-1.385^{* *}$ & 0.699 & 0.048 \\
\hline 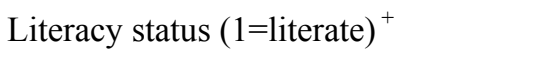 & $-1.397^{*}$ & 0.840 & 0.096 \\
\hline Membership in farmers' association $^{+}$ & -0.446 & 0.840 & 0.598 \\
\hline Use improved Seeds ${ }^{+}$ & 0.341 & 0.768 & 0.658 \\
\hline Access to $\mathrm{Credit}^{+}$ & -0.191 & 0.885 & 0.829 \\
\hline Distance from home to farm (km) & 0.433 & 0.310 & 0.162 \\
\hline Access to extension services $^{+}$ & 0.737 & 0.862 & 0.393 \\
\hline Household is insured $^{+}$ & 1.006 & 0.806 & 0.212 \\
\hline Ln (Non-farm income) & 0.048 & 0.074 & 0.515 \\
\hline Constant & 2.047 & 1.607 & 0.203 \\
\hline Vsigmas & $-0.522 * * *$ & 0.088 & 0.000 \\
\hline Sigma_V_sqr & $0.593 * * *$ & 0.052 & 0.000 \\
\hline \multirow[t]{2}{*}{ Wald test (Chi2 (3)) } & 124.63 & & 0.000 \\
\hline & Mean & Min & Max \\
\hline Technical Efficiency & 0.837 & 0.272 & 0.994 \\
\hline
\end{tabular}


Table 2 also shows that the inefficiency component of the error term is significantly different from zero, which indicates that technical inefficiency (TI) is indeed stochastic and that inefficiency is an important contributor to observed groundnut output variability (i.e., Ho: Sigma_u $=0$ is rejected). The distribution of technical efficiency (Figure 1) is asymmetric and tilted to the right, which shows that the majority of farmers have a high level of efficiency in groundnut production in Senegal. Average TE score is $83.70 \%$ for the pooled sample.

The estimated determinants of TE are summarized and presented in table 2. Age, gender and education are all statistically significant. Age is positively related to TE suggesting that older farmers who are assumed to have more experience in farming are more technical efficient than younger farmers. This result confirms the findings of Kinkingninhoun-Mêdagbé et al. (2010), Gebregziabher et al. (2012), Abate et al. (2014). Education may enhance farmers' ability to interpret and make good use of information about markets and prices in environments where such attributes are particularly necessary (Ahmed et al., 2002). Male-headed households have higher TE than their female counterparts. Household head literacy is positively and significantly related to TE, implying that education is an important factor to enhance TE in Senegal. This result agrees with those of Mariano et al (2011), Gebregziabher et al. (2012), Abate et al. (2014). Credit is positive but not significantly related to TE. Extension contact and improved seeds are negative and not significant.

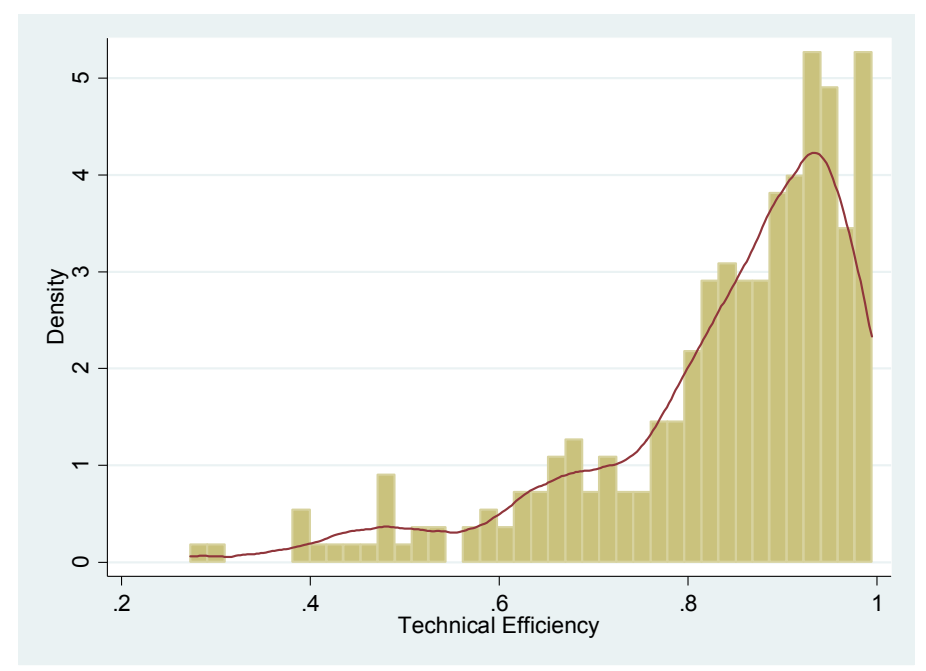

Figure 1. Distribution of Technical efficiency score

\subsection{Impact of the Weather Index Insurance on Technical Efficiency}

This paper aims at measuring the average impact of the weather index insurance on groundnut farmers' technical efficiency. In other words, we estimate the Average Treatment Effect on the Treated (ATT), where the treatment is participation to the weather index insurance program and the treated are farmers who take up the insurance. We used five nearest neighbor without replacement and kernel matching methods to estimate the ATT. Table 3 presents the results of the balancing test before and after the matching for both Nearest Neighbor and Kernel matching methods. The matching was done using farmers' intrinsic characteristics such as age, gender, literacy, membership in farmers' association and access to extension services. The rational behind choosing these characteristics is that they can potentially affect the likelihood of taking up the weather index insurance (Abate and al., 2014) as well as affecting farm TE and thus obey to the conditional independent assumption. Table 3 shows that, there is no statistical significant difference between beneficiaries and control farmers after the matching. Hence, the results suggest that our comparison is valid from statistical point of view. 
Table 3. Balancing test estimates for Nearest Neighbor and Kernel Matching

\begin{tabular}{|c|c|c|c|c|c|c|}
\hline \multirow{3}{*}{ Variable } & \multicolumn{6}{|c|}{ Nearest-Neighbor Matching } \\
\hline & \multirow{2}{*}{$\begin{array}{l}\text { Unmatched } \\
\text { Matched }\end{array}$} & \multicolumn{2}{|c|}{ Mean } & \multirow[b]{2}{*}{$\%$ Bias } & \multicolumn{2}{|c|}{ T-test } \\
\hline & & Treated & Control & & T-stat. & P-value \\
\hline \multirow{2}{*}{ Age of household head } & Unmatched & 42.28 & 42.64 & -2.8 & -0.22 & 0.822 \\
\hline & Matched & 42.79 & 41.36 & 11.5 & 0.82 & 0.412 \\
\hline \multirow{2}{*}{ Gender of household head } & Unmatched & 0.77 & 0.86 & $-23.6^{* *}$ & -1.99 & 0.04 \\
\hline & Matched & 0.84 & 0.89 & -13.7 & -1.07 & 0.286 \\
\hline \multirow{2}{*}{ Alphabetise } & Unmatched & 0.27 & 0.34 & -14.8 & -1.2 & 0.231 \\
\hline & Matched & 0.27 & 0.28 & -3.6 & 0.26 & 0.798 \\
\hline \multirow{2}{*}{ Cooperative membership } & Unmatched & 0.74 & 0.24 & $112.9 * * *$ & 9.28 & 0.0001 \\
\hline & Matched & 0.71 & 0.72 & -0.5 & -0.03 & 0.975 \\
\hline \multirow{3}{*}{ Access to vulgarization service } & Unmatched & 0.22 & 0.16 & 13.3 & 1.11 & 0.269 \\
\hline & Matched & 0.21 & 0.26 & -11 & -0.71 & 0.481 \\
\hline & \multicolumn{6}{|c|}{ Kernel Matching } \\
\hline \multirow{2}{*}{ Age of household head } & Unmatched & 42.28 & 42.64 & -2.8 & -0.22 & 0.822 \\
\hline & Matched & 42.79 & 42.24 & 4.4 & 0.32 & 0.751 \\
\hline \multirow{2}{*}{ Gender of household head } & Unmatched & 0.77 & 0.86 & $-23.6^{* *}$ & -1.99 & 0.047 \\
\hline & Matched & 0.84 & 0.85 & -3.1 & -0.23 & 0.818 \\
\hline \multirow{2}{*}{ Alphabetise } & Unmatched & 0.27 & 0.34 & -14.8 & -1.2 & 0.231 \\
\hline & Matched & 0.27 & 0.31 & -10.1 & -0.71 & 0.478 \\
\hline \multirow{2}{*}{ Cooperative membership } & Unmatched & 0.74 & 0.24 & $112.9 * * *$ & 9.28 & 0.0001 \\
\hline & Matched & 0.71 & 0.72 & -1.1 & -0.07 & 0.942 \\
\hline \multirow{2}{*}{ Access to vulgarization service } & Unmatched & 0.22 & 0.16 & 13.3 & 1.11 & 0.269 \\
\hline & Matched & 0.21 & 0.23 & -3.2 & -0.21 & 0.833 \\
\hline
\end{tabular}

*** significant at $1 \%, * *$ significant at $5 \%$ level and * significant at $10 \%$ level

Figure 2 shows kernel density estimates of the distribution of propensity scores for beneficiaries and control farmers.

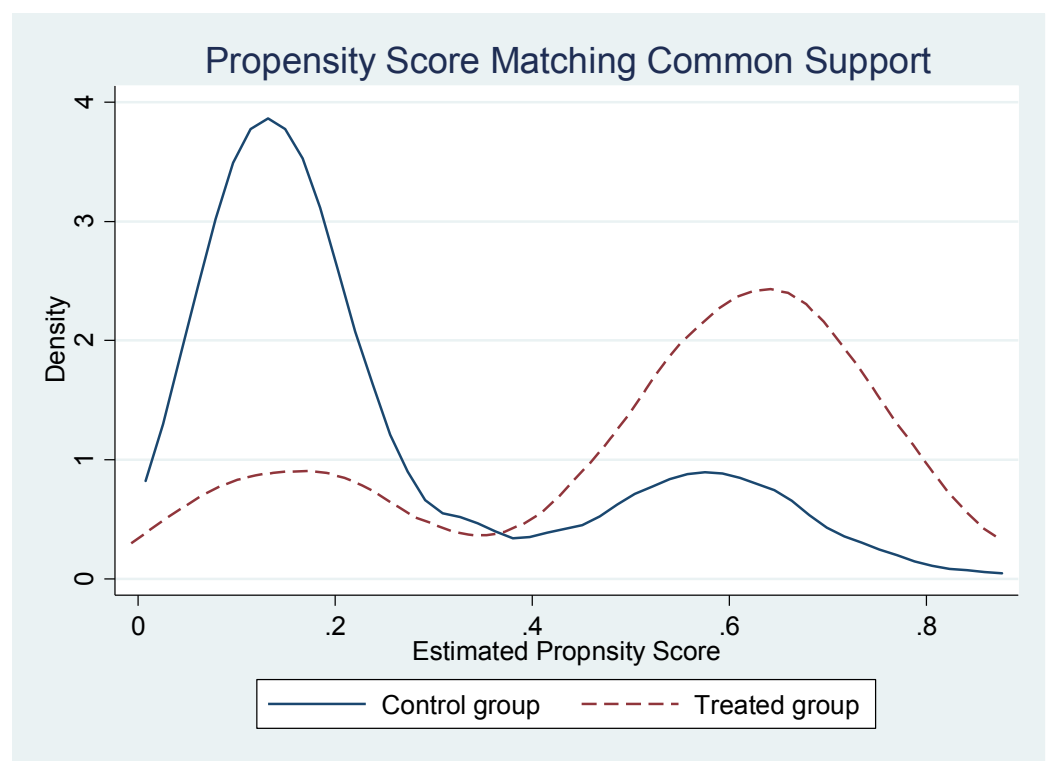

Figure 2. Kernel density of propensity scores by treatment status 
To improve the robustness of the estimate, the matches are restricted to insured farmers and uninsured farmers who have a common support in the distribution of the propensity score. The common support is typically the values of the propensity scores where both treatment (i.e., insured farmers) and control groups (i.e., uninsured farmers) are found. A total of 19 farmers were found off-support and were dropped. Hence, the matched sample includes 286 farmers, 96 of whom are in the treatment group and 190 in the control group.

The average impact of the weather index insurance on the technical efficiency of smallholder groundnut farmers is analysed using the matched sample. The resulting estimate of the Average Treatment Effect on the Treated (ATT) of weather index insurance on the technical efficiency of smallholder farmers, based on the Propensity Score Matching (PSM) methods, is reported in Table 4.

Table 4. Impact of weather index insurance on technical efficiency of groundnut smallholders

\begin{tabular}{lccccccc}
\hline \multicolumn{7}{c}{ Nearest Neighbor matching estimates ATT } \\
& Treated & Controls & Difference & SE & Percentage & T-stat & Obs. \\
\hline Full sample & 0.797 & 0.855 & $-0.058^{* * *}$ & 0.017 & $-6.783 \%$ & -3.390 & 305 \\
ATT & 0.810 & 0.858 & $-0.048^{* *}$ & 0.023 & $-5.594 \%$ & -2.06 & 286 \\
\hline \multicolumn{7}{c}{ Kernel Matching estimates ATT } \\
& Treated & Controls & Difference & SE & Percentage & T-stat & Obs. \\
\hline Full sample & 0.797 & 0.855 & $-0.058^{* * *}$ & 0.017 & $-6.783 \%$ & -3.390 & 305 \\
ATT & 0.810 & 0.867 & $-0.057^{* *}$ & 0.022 & $-6.574 \%$ & -2.58 & 286 \\
\hline
\end{tabular}

*** Significant at $1 \%,{ }^{* *}$ significant at $5 \%$ level and * significant at $10 \%$ level; Bootstrap with 500 replications is used to estimate the standard errors

The results suggest that weather index insurance has negative impact on groundnut farmers' technical efficiency. In other words, uninsured farmer show consistently higher average TE score than insured farmers. The impact estimates are robust across different estimation methods. The TE gap is about 5.6 percent with the Five Nearest-Neighbor matching method and 6.6 percent with the Kernel matching.

While the PSM method control for biases stemming from observed variables, if there are unobserved variables, which affect participation in the insurance program and technical efficiency simultaneously, unobserved heterogeneity affecting the robustness of the estimates might arise (Rosenbaum and Rubin 1983; Rosenbaum, 2002; Becker and Caliendo, 2007). We test the presence of this problem using Rosenbaum bounds sensitivity analysis. The sensitivity analysis results are showed in Table 5 and Table 6 respectively for the Five Nearest Neighbor and Kernel matching methods. The results indicate that, it is not likely that the estimated impacts of the weather index insurance are driven by unobservable characteristics that determine participation to the insurance program and technical efficiency, which the propensity score matching does not address. The higher TE score from uninsured farmers will still be significant at $1 \%$ level even if there are unobservable characteristics that increase the likelihood of taking up the insurance by a factor ${ }^{1}$ of 2 or more.

Table 5. Rosenbaum Bounds sensitivity analysis for hidden bias for Kernel PSM

\begin{tabular}{lcccccc}
\cline { 2 - 7 } Gamma & sig + & sig- & t-hat + & t-hat- & CI + & CI- \\
\hline 1 & $1.7 \mathrm{e}-07$ & $1.7 \mathrm{e}-07$ & -0.0409 & -0.04098 & -0.05882 & -0.02484 \\
1.5 & $2.0 \mathrm{e}-12$ & 0.000264 & -0.05599 & -0.02692 & -0.07658 & -0.01169 \\
1.8 & $2.0 \mathrm{e}-15$ & 0.002692 & -0.06319 & -0.02064 & -0.08767 & -0.00660 \\
2 & 0 & 0.008215 & -0.06722 & -0.01706 & -0.09534 & -0.00349 \\
\hline
\end{tabular}

gamma (log odds of differential assignment due to unobserved factors); sig+ (upper bound significance level); sig- (lower bound significance level; t-hat + - upper bound Hodges-Lehmann point estimate); t-hat- (lower bound Hodges-Lehmann point estimate); $\mathrm{CI}+$ (upper bound confidence interval $(\mathrm{a}=.95)$ ); CI- (lower bound confidence interval $(\mathrm{a}=.95))$

\footnotetext{
${ }^{1}$ Even when gamma is equal to 2, sig + is still significant at $1 \%$ level for the Nearest-Neighbor and the kernel Matching methods
} 
Table 6. Rosenbaum Bounds sensitivity analysis for hidden bias for nearest-neighbor PSM

\begin{tabular}{lcccccc} 
Gamma & sig + & sig- & t-hat + & t-hat- & CI + & CI- \\
\hline 1 & $4.5 \mathrm{e}-08$ & $4.5 \mathrm{e}-08$ & -0.035284 & -0.035284 & -0.051161 & -0.022297 \\
1.5 & $3.2 \mathrm{e}-13$ & 0.0001 & -0.048969 & -0.023437 & -0.067486 & -0.012563 \\
1.8 & $2.2 \mathrm{e}-16$ & 0.001173 & -0.054897 & -0.019409 & -0.07605 & -0.007918 \\
2 & 0 & 0.003875 & -0.05859 & -0.016775 & -0.081411 & -0.005381 \\
\hline
\end{tabular}

gamma (log odds of differential assignment due to unobserved factors); sig+ (upper bound significance level); sig- (lower bound significance level; t-hat + - upper bound Hodges-Lehmann point estimate); t-hat- (lower bound Hodges-Lehmann point estimate); $\mathrm{CI}+$ (upper bound confidence interval $(\mathrm{a}=.95)$ ); CI- (lower bound confidence interval $(\mathrm{a}=.95))$

Our finding suggests that weather index insurance alone is not enough to improve farmer TE. From a policy perspective, weather index insurance programs targeting smallholder farmers in developing countries, and in particular in sub-Saharan Africa, should be accompanied with education services, provision of new technologies such as high yield seeds and other best farm management practices and credit to help farmers better adapt to weather shocks and secure their production and income.

\section{Conclusion and Recommendations}

The high volatility of rainfall and temperature, drought, insect invasions and plant biological diseases are climatic factors that affect agricultural yields of smallholder farmers in developing countries in sub-Saharan Africa. The management of these bioclimatic risks has become importance priority in the development agent of international institutions and non-governmental organizations to secure farmers' income, ensure food security and alleviate poverty. In this perspective, in recent years, weather index insurance program targeting smallholder farmers has been implemented in several developing countries.

In this paper, we investigated the impact of the weather index insurance program on smallholder farmers' technical efficiency, with a focus on groundnut farmers in Senegal. A Cobb-Douglas stochastic production frontier technology was adopted to estimate the TE scores. The Nearest Neighbor and kernel matching methods were used to estimate the ATT and to address potential bias stemming from observed variables.

The results showed that land, labor and seeds have positive and significant impact on Groundnut production in Senegal. The average TE score for the unmatched sample is $84 \%$ suggesting that groundnut farmers could increase their production by $16 \%$ while keeping constant the amount of input use. Age, gender and education were found to be significantly related to technical efficiency, while membership in farmers' association, credit, improved seeds and extension contact were not significantly related to technical efficiency.

The estimated impact of weather index insurance on technical efficiency showed that uninsured farmers have higher average TE than insured farmers. The TE gap range from 5.6 percent to 6.6 percent depending on the matching method considered. This finding suggests that, the provision of weather index insurance to farmers in developing countries is insufficient to improve their TE. From a policy perspective, we suggest that weather index insurance programs targeting smallholder farmers in developing countries, and in particularly in sub-Saharan Africa, be accompanied with education services, provision of new technologies such as high yield seeds and other best farm management practices and credit to help farmers better adapt to weather shocks and secure their production and income.

\section{Acknowledgments}

The authors express special gratitude to John Sumbo Balanko for copyediting. Special thanks go to anonymous reviewers for helpful comments. Our gratitude goes to Komlan Amen Dodge for data collection and management.

\section{References}

Abate, G. T., Francesconi, G. N., \& Getnet, K. (2014). Impact of agricultural cooperatives on smallholders' technical efficiency: empirical evidence from Ethiopia. Annals of Public and Cooperative Economics, 85, 257-286. https://doi.org/10.1111/apce.12035

Abdulai, A., \& Tietje, H. (2007). Estimating technical efficiency under unobserved heterogeneity with stochastic frontier models: application to northern German dairy farms. European Review of Agricultural Economics, 
34, 393-416. https://doi.org/10.1093/erae/jbm023

Ahmed, M. M., Gebremedhin, B., Benin, S., \& Ehui, S. (2002). Measurement of Sources of technical efficiency of land tenure contracts in Ethiopia. Environmental and Development Economics, 7(3), 507-527. https://doi.org/10.1017/S1355770X0200030X

Atici, K. B., \& Podinovski, V. V. (2015). Using data envelopment analysis for the assessment of technical efficiency of units with different specialisations: An application to agriculture. Omega, 54, 72-83. https://doi.org/10.1016/j.omega.2015.01.015

Battese, G. E., \& Coelli, T. J. (1995). A model for technical inefficiency effects in a stochastic frontier production function for panel data. Empirical economics, 20, 325-332. https://doi.org/10.1007/BF01205442

Becker, S. O., \& Ichino, A. (2002). Estimation of average treatment effects based on propensity scores. The stata journal, 2(4), 358-377.

Becker, S., \& Caliendo, M., (2007). Sensitivity analysis for average treatment effects. The Stata Journal, 7, 7183.

Bernard, T., Taffesse, A. S., \& Gabre - Madhin, E. (2008). Impact of cooperatives on smallholders' commercialization behavior: evidence from Ethiopia. Agricultural Economics, 39(2), 147-161. https://doi.org/10.1111/j.1574-0862.2008.00324.x

Bravo-Ureta, B. E., \& Pinheiro, A. E. (1993). Efficiency analysis of developing country agriculture: a review of the frontier function literature. Agricultural and resource economics Review, 22, 88-101. https://doi.org/10.1017/S1068280500000320

Burke, M., de Janvry, A., \& Quintero, J. (2010). Providing Index-Based Agricultural Insurance to Smallholders: Recent Progress and Future Promise. Documento de Trabajo. CEGA, University of California at Berkeley.

Carter, M., de Janvry, A., Sadoulet, E., \& Sarris, A. (2014). Index-based weather insurance for developing countries: A review of evidence and a set of propositions for up-scaling (No. P111).

Čechura, L. (2010). Estimation of technical efficiency in Czech agriculture with respect to firm heterogeneity. Agricultural Economics, 56, 183-191.

Chen, Z., \& Song, S. (2008). Efficiency and technology gap in China's agriculture: A regional meta-frontier analysis. China Economic Review, 19, 287-296.

Chetaille, A., \& Lagrande, D. (2010). L'assurance indicielle, une réponse face aux risques climatiques? Inter-réseau développement rurale.

Clarke, D. J., Clarke, D., Mahul, O., Rao, K. N., \& Verma, N. (2012). Weather based crop insurance in India. https://doi.org/10.1016/j.chieco.2007.03.001

Coelli, T., \& Perelman, S. (1996). Efficiency measurement, multiple-output technologies and distance functions: With application to European Railways (No. DP 1996/05). CREPP.

Cole, S., Bastian, G., Vyas, S., Wendel, C., \& Stein, D. (2012). The effectiveness of index-based micro-insurance in helping smallholders manage weather-related risks. London: EPPI-Centre, Social Science Research Unit, Institute of Education, University of London.

D'Agostino, R. B. (1998). Tutorial in biostatistics: propensity score methods for bias reduction in the comparison of a treatment to a non-randomized control group. Stat Med, 17(19), 2265-2281. https://doi.org/10.1002/(SICI)1097-0258(19981015)17:19<2265::AID-SIM918>3.0.CO;2-B

Dehejia, R. H., \& Wahba, S. (2002). Propensity score-matching methods for nonexperimental causal studies. The review of economics and statistics, 84(1), 151-161. https://doi.org/10.1162/003465302317331982

Duflo, E., Glennerster, R., \& Kremer, M. (2007). Using randomization in development economics research: A toolkit. Handbook of development economics, 4, 3895-3962. https://doi.org/10.1016/S1573-4471(07)04061-2

Erec Heimfarth, L., \& Musshoff, O. (2011). Weather index-based insurances for farmers in the North China Plain: An analysis of risk reduction potential and basis risk. Agricultural Finance Review, 71, 218-239. https://doi.org/10.1108/00021461111152582

Francesconi, G. N., \& Heerink, N. (2010). Ethiopian agricultural cooperatives in an era of global commodity exchange: does organisational form matter? Journal of African Economies, 20(1), 153-177. https://doi.org/10.1093/jae/ejq036 
Gebregziabher, G., Namara, R. E., \& Holden, S. (2012). Technical efficiency of irrigated and rain-fed smallholder agriculture in Tigray, Ethiopia: A comparative stochastic frontier production function analysis. Quarterly Journal of International Agriculture, 51, 203.

Godtland, E. M., Sadoulet, E., Janvry, A. D., Murgai, R., \& Ortiz, O. (2004). The impact of farmer field schools on knowledge and productivity: A study of potato farmers in the Peruvian Andes. Economic development and cultural change, 53(1), 63-92. https://doi.org/10.1086/423253

Hazell, P., \& Skees, J. R. (2006). Insuring against bad weather: Recent thinking. India in a Globalising World: Some Aspects of Macroeconomy, Agriculture, and Poverty, New Delhi: Academic Foundation.

Hazell, P., Anderson, J., Balzer, N., Hastrup Clemmensen, A., Hess, U., \& Rispoli, F., (2010). L'assurance basée sur un indice climatique: potentiel d'expansion et de durabilité pour l'agriculture et les moyens de subsistance en milieu rural. Rapport pour le Programme Alimentaire Mondial (PAM) et Fonds International de Développement Agricole (FIDA).

Heckman, J. J., Ichimura, H., \& Todd, P. E. (1997). Matching as an econometric evaluation estimator: Evidence from evaluating a job training programme. The review of economic studies, 64(4), 605-654. https://doi.org/10.2307/2971733

Iheke, O. R. (2008). Technical efficiency of cassava farmers in South Eastern Nigeria: Stochastic frontier approach. Agricultural journal, 3, 152-156.

Jehle, G. A., \& Reny, P. J. (2011). Advanced Microeconomic Theory. Harlow, England, New York: Financial Times.

Khai, H. V., \& Yabe, M. (2011). Technical efficiency analysis of rice production in Vietnam. Journal of ISSAAS, $17,135-146$.

Khan, A., Huda, F. A., \& Alam, A. (2010). Farm household technical efficiency: A study on rice producers in selected areas of Jamalpur district in Bangladesh. European Journal of Social Sciences, 14, 262-271.

Kinkingninhoun-Mêdagbé, F. M., Diagne, A., Simtowe, F., Agboh-Noameshie, A. R., \& Adégbola, P. Y. (2010). Gender discrimination and its impact on income, productivity, and technical efficiency: evidence from Benin. Agriculture and human values, 27, 57-69. https://doi.org/10.1007/s10460-008-9170-9

Kumbhakar, S. C., Tsionas, E. G., \& Sipiläinen, T. (2009). Joint estimation of technology choice and technical efficiency: an application to organic and conventional dairy farming. Journal of Productivity Analysis, 31, 151-161. https://doi.org/10.1007/s11123-008-0081-y

Kumbhakar, S. C., Wang, H., \& Horncastle, A. P. (2015). A practitioner's guide to stochastic frontier analysis using Stata. Cambridge University Press.

Leblois, A., \& Quirion, P. (2013). Agricultural insurances based on meteorological indices: realizations, methods and research challenges. Meteorological Applications, 20, 1-9. https://doi.org/10.1002/met.303

Liverpool-Tasie, L. S. O., Adjognon, S., \& Kuku-Shittu, O. (2015). Productivity effects of sustainable intensification: The case of Urea deep placement for rice production in Niger State, Nigeria. African Journal of Agricultural and Resource Economics Volume, 10(1), 51-63.

Mahul, O., Verma, N., \& Clarke, D., (2012). Improving farmers' access to agricultural insurance in India.

Mariano, M. J., Villano, R., \& Fleming, E. (2011). Technical Efficiency of Rice Farms in Different Agroclimatic Zones in the Philippines: An Application of a Stochastic Metafrontier Model. Asian Economic Journal, 25, 245-269. https://doi.org/10.1111/j.1467-8381.2011.02060.x

Meeusen, W., \& van Den Broeck, J. (1977). Efficiency estimation from Cobb-Douglas production functions with composed error. International economic review, 435-444. https://doi.org/10.2307/2525757

Muller, B., Sall, M., Leblois, A., Balde, A., Fall, M., Kouakou, P., \& Affholder, F. (2012). L'assurance agricole indicielle en afrique de l'ouest: principes, premières réalisations et perspectives.

O’Donnell, C. J., Rao, D. P., \& Battese, G. E. (2008). Metafrontier frameworks for the study of firm-level efficiencies and technology ratios. Empirical Economics, 34, 231-255. https://doi.org/10.1007/s00181-007-0119-4

Oum, T. H., Yan, J., \& Yu, C. (2008). Ownership forms matter for airport efficiency: A stochastic frontier investigation of worldwide airports. Journal of urban Economics, 64, 422-435. https://doi.org/10.1016/j.jue.2008.03.001 
Rahman, S., \& Rahman, M. (2009). Impact of land fragmentation and resource ownership on productivity and efficiency: The case of rice producers in Bangladesh. Land Use Policy, 26, 95-103. https://doi.org/10.1016/j.landusepol.2008.01.003

Rosenbaum, P. R. (2002). Observational Studies (2nd ed.). New York, NY: Springer. https://doi.org/10.1007/978-1-4757-3692-2

Rosenbaum, P. R., \& Rubin D. B. (1985). Constructing a control group using multivariate matched sampling methods that incorporate the propensity score. American Statistician, 39, 33-38. https://doi.org/10.1080/00031305.1985.10479383

Rosenbaum, P. R., \& Rubin, D. B. (1983). The Central Role of the Propensity Score in Observational Studies for Causal Effects. Biometrika, 70(1), 41-55. https://doi.org/10.1093/biomet/70.1.41

Sivakumar, M. V., \& Motha, R. P. (2008). Managing weather and climate risks in agriculture. Springer Science $\&$ Business Media.

Smith, J., \& Todd, P. (2005). Does matching overcome Lalonde's critique of nonexperimental estimators? Journal of Econometrics, 125, 305-353. https://doi.org/10.1016/j.jeconom.2004.04.011

Tchale, H. (2009). The efficiency of smallholder agriculture in Malawi. African Journal of Agriculture and Resource Economics, 3, 101-121.

Todd, P. E. (2006). Matching estimators'. Retrieved June, 2017, from http://athena.sas.upenn.edu/petra/papers/mpalgrave2.pdf

\section{Copyrights}

Copyright for this article is retained by the author(s), with first publication rights granted to the journal.

This is an open-access article distributed under the terms and conditions of the Creative Commons Attribution license (http://creativecommons.org/licenses/by/4.0/). 